This has helped Elsyca to create a unique integrated-value proposition based on virtual design. Elsyca's approach allows

\section{Elsyca has} proven that...

\section{an academic}

$$
\begin{aligned}
& \text { spin-off can } \\
& \text { become a }
\end{aligned}
$$

\section{niche market.}

$$
\text { leader in a }
$$
customers to model their electrochemical reality, accounting for the physico-chemical parameters of the electrolyte bath, the complete geometry of the electrochemical cell, the electrode reactions and all process parameters ranging from flow rates to DC or pulse reverse parameters. This methodology is applied and encapsulated in all of Elsyca's engineering services and software solutions. Moreover, product development is highly application-oriented, led by customer requirements in several markets.

In 2003, Elsyca reached

the commercial and technical targets that were included in the business plan. For 2004, the revenues and growth rate are expected to exceed the business plan.

\section{Conclusion}

Elsyca has proven that despite the lack of size, resources and a new undiscovered market, an academic spin-off can become a leader in a niche market. The focus of the VUB/VKI research and the ability to identify meaningful applications are important success factors. However, equally or even more important is the fact that Elsyca started as a consulting company. This was not only a way to generate cash in the early days of the company but it has also put the engineers in direct contact with the market and the customers. Since Elsyca had (and still has) to create its own new market this is more valuable than any overpriced marketanalysis report. Finally the team had the vision to hire commercial and business oriented people and to look for external financing at the right moment. Today Elsyca has the talent and the team to implement its vision and move to the next stage of their development: to become a global leader in electrochemical intelligence.

\section{About the authors}

Johan Deconinck received his M. Sc. Degree in Electromechanical Engineering from the VUB, in 1976 and the PhD degree in Applied Sciences in 1985. Since 1998 he is professor of Electrical Engineering and Electromagnetic Field Theory of the VUB and is head of a research group performing "numerical electrochemistry".

Leslie Bortels received his M.Sc. degree in electrical engineering from the VUB in 1992 and his Ph.D. degree in electrical engineering in 1996. He joined the Electrotechnics Department from Technical VUB in 1992. He is a NACE certified cathodic protection technician.

Frank Gielen received a Master degree in Telecommunication System Engineering from the Royal Military Academy in Brussels (1985) and has a Ph.D. in Computer Science from the VUB (1993). Since 2002 he is senior investment manager of BI3, the seed capital fund of the VUB, where he is responsible for dealflow generation, capital raising and hands-on interim VUB management activities for the newly created spin-offs.

\section{At the crossroads of} \section{physics and archaeology: the OSIRIS Project}

\author{
Y. Renotte ${ }^{a}$, D. Laboury ${ }^{b}, B$. Tilkens ${ }^{a}$, V. Moreau ${ }^{a}$, M. Morant ${ }^{c}$
}

a Hololab, Dept. of Physics, University of Liège, allée du 6 Août, $17, B-4000$ Liège, Belgium

${ }^{b}$ Egyptological Dept. and European Center for Archaeometry of the University of Liège (ECA), University of Liège, quai Roosevelt, 1B, B-4000 Liège, Belgium

'Interface Entreprises-Université de Liège, quai Van Beneden, 25, B-4020 Liège, Belgium

$A$ rchaeology, as the Science which studies the material remains Hof human behaviour, naturally stands at one of the crossroads between the human Sciences and Science (physics, chemistry, biology, etc). This connection is precisely a way to define what nowadays it is customary to call Archaeometry, that is the combination of laboratory techniques with the traditional methodology of the historical and archaeological investigation to deepen the analysis, the knowledge and the interpretation of ancient works of art, monuments and archaeological objects. Archaeology is also permanently confronted with the problem of recording the objects of its study, since excavated relics of the past are always exposed to a progressive and often irremediable process of defacement, and, finally of annihilation. In order to find a solution to this important and still unresolved problem, the OSIRIS Project aims to develop one or several devices that allow by optoelectronic process-

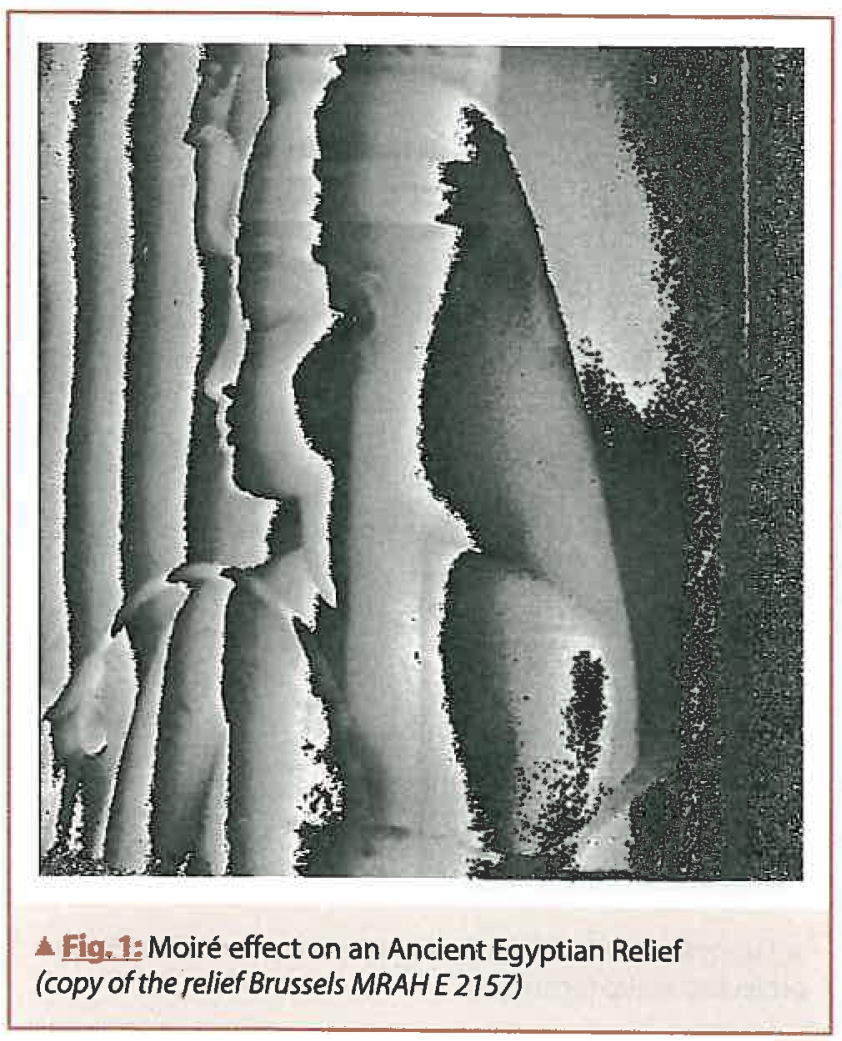


es an accurate, quick and easy to use, recording dedicated to the specific and demanding needs of archaeological research.

\section{The traditional recording techniques in archaeology and art history [1-6]}

The recordings needed by the different aspects of Archaeological research have a double aim: the creation of a medium that allows one to display in a more accurate way the object studied; and, even more importantly, the virtual conservation of this object, or, at least, the conservation of the historical information it reveals and preserves.

The conservation of archaeological objects is far from simply being a theoretical problem. Indeed, in its very process of revealing the relics of the past, Archaeology is by definition destructive: it always destroys the containment of the object it aims to reveal.

To counter this progressive and irremediable annihilation of the material remains of the past, Archaeology uses different recording techniques like photography, drawing... But all these techniques have a common rather poor flexibility and an unavoidable dependence on the subjectivity of reading and rendering of a human operator (Traunecker [6], 1987; Loeben [4], 1996).

Recording in Archaeology and Art History raises two essential problems, related one to the other: on the one hand, the objectivity, and on the other, the speediness and the flexibility of realisation.

\section{The solutions offered by numeric image and optoelectronic technologies}

To overcome these inherent constraints of the traditional recording techniques, it is necessary to use new technologies of recording, processing and storing the data that define the precise 3D shape of any archaeological object.

Nowadays, numeric image technology offers an almost infinite flexibility of use. Recent developments in Optoelectronics now allow a real global 3D recording that is at the same time faster and more reliable. These new technologies give enormous advantages regarding the flexibility and the ease of recording, processing, reading and storing; they also offer the possibility to

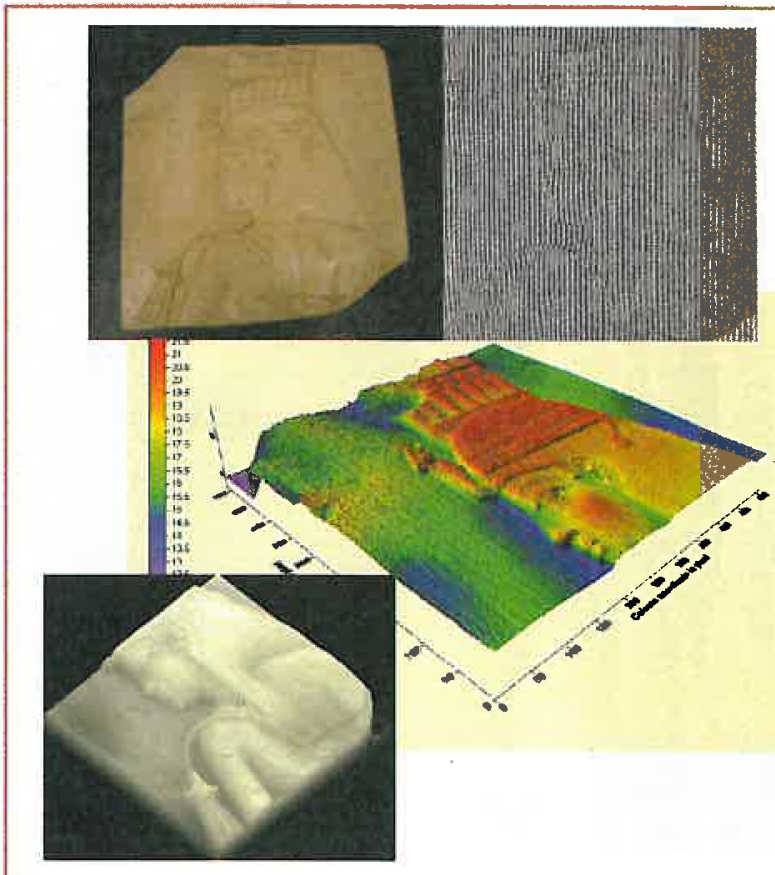

Aig. 2: Detail of a 3D recording of the same relief with the projected moiré technique. imagine new ways of publishing ancient monuments, in an electronic form that is more realistic, more accurate and more interactive, as a real 3D structure and not anymore by means of fixed and inaccurate $2 \mathrm{D}$ images.

\section{The available techniques [3-6]}

There exist a few projects of global scanning of ancient artefacts (Clarke [3], 1998; Taubes [5], 1999). But, until now, none of the already available techniques is able to work in real in situ conditions (for example under the sunshine of Egypt), on a large scale, and with the precision needed for archaeological and art historical research.

For example the optical recording of the relief of an object can be achieved by the well-known linear scanning method. Many tests have revealed that it is very difficult to use this system with high precision in aggressive environmental conditions such as those found in many archaeological sites.

The main problem of the scanning method, that is the problem of moving precisely the scanning laser line, can be eliminated by projecting a constructed pattern or a grid instead of one single line. Its deformation is then used as the probe of the relief. This light pattern has to be periodically structured and static, based on a grid that is alternatively light and dark. One projects it on the surface to be analysed. By recording the scene with a CCD/CMOS camera, it is possible to superimpose the image of the grating modified by the relief with the reference image. This process creates geometrical shapes (Figure 1); it is the Moiré effect.

The interpretation of these Moiré pictures gives the whole relief information of the analysed object (Figure 2). The accuracy of this technique is comparable with the accuracy of the traditional laser scanning but its process is much faster, since a surface of one square meter can be analysed at one time. Besides, the elimination of the problems linked to the precise and regular moving of the laser line makes it much easier to use in difficult in situ conditions. The Moiré technique perfectly fulfils the requirements of archaeological recording: fast acquisition, accuracy, robustness and flexibility, necessary to allow working on site, in aggressive environmental conditions.

\section{Results of the OSIRIS Project}

As a conclusion to this work, the European Centre for Archaeometry of the University of Liège, with the Hololab Laboratory have developed together a complete portable set-up (combining the whole optoelectronic acquisition and data processing) specifically dedicated to the quick and accurate numerical 3D recording of archaeological documents. It uses the projected Moiré technique. This project is named OSIRIS (Optical Systems for Interferometric Relief Investigation and Scanning), in a reference to Ancient Egypt's heritage, whose study was at the root of the above mentioned research*. For this application in the field of archaeology and art history, the following conditions have been defined:

Depth resolution: $0.1 \mathrm{~mm}$; lateral resolution: $0.3 \mathrm{~mm}$

- Depth range $20 \mathrm{~cm}$

Acquisition surface $50 \times 50 \mathrm{~cm}^{2}-1 \mathrm{~m}^{2}$

- Adaptation to on site working conditions (temperature, sunlight, ...)

- Flexibility and easiness of transport and use

- Complete processing software (acquisition, multiple 3D visualisation possibilities, modelling, metrology, computer assisted interpretation, automatic features extraction, ...)

*Furthermore, Osiris is precisely the Ancient Egyptian God of periodical and cyclical phenomenon. 
Since these conditions are very demanding in comparison with the capabilities of $3 \mathrm{D}$ recording devices already available, other fields of application are under consideration.

The results of the OSIRIS Project allow us to imagine for the near future new possibilities for scholarly publication of ancient monuments, i. e. in an interactive digital 3D virtual reality, directly usable for scientific research, as if one was actually in front of the real object.

\section{From the OSIRIS Project to the DEIOS Company}

Since 1998, the policy of the University of Liège has been to boost spin-off activities. An internal regulation has clarified the rules for researchers for intellectual property (IP) rights and for setting up companies. In 1999, Spinventure was established in a 50/50 based joint venture between Gesval and the local public investment company Meusinvest. Spinventure is a pre-seed and seed capital fund, only focused on high-tech companies. Together, they have set up more than 35 companies in 5 years.

In addition, an incubator dedicated to physical science and engineering has been installed in the Liege Science Park, just near the campus : Wallonia Space Logistics (W.S.L) can provide not only pre-seed financing, but also full support for starting a company, with space, logistic support and mainly commercial support.

On another hand, the entrepreneurial spirit is diffused in the research community through seminars, courses and events organised by the Entrepreneurship Centre of the Business School of the University (SEED).

In due time, the research team has entered in touch with the Technology Transfer Office of the University (Interface Enterprises-University and Gesval, an affiliated company of the University of Liège in charge of technology transfer) in order to build a IP strategy within the research project.. IP mapping has been set up by the Patlib Centre, which is an internal service of the TT Office. Of course, the research team had to maintain full confidentiality for their project, including scientific publications or

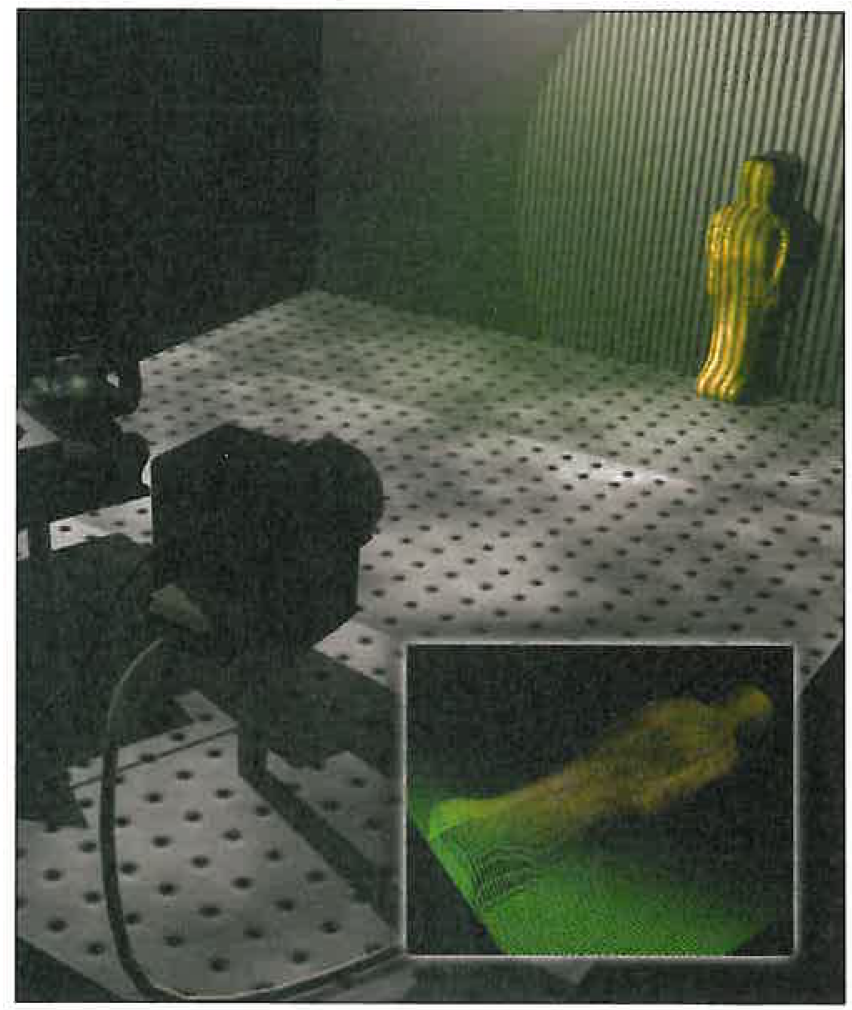

connexions with possible investors. This is a necessary choice of the team, until the patent application is consolidated by the patent manager. Several provisional applications have been decided in order to get finally a package of technical and patentable information available for the patenting procedure.

For obtaining more practical results, the Walloon government proposes the so-called First Spin Off program, aimed at finalising the research up to a functional product. Such a program enabled one to obtain a prototype of the Osiris device.

Then Gesval and the TT office help the research team to set up a step-by-step business plan, and to enter into connection with other players.

At the end, Gesval brings the technology to the new company, Spinventure brings money, researchers bring money too, and the first round is completed by experienced people from industry, investing and acting as coaches.

\section{Conclusion}

The projection and the reading of the pattern of fringes is made by an original set-up based on a Diffractive Optical Element System [7-8].

Today the OSIRIS Project has given rise to the so-called startup DEIOS (Development and Enhancement of Interferometric Optical Systems) which develops the scanning tools (Figure 3). Deios was established by early 2004, with a total capital of Euro 500.000 , and is installed in the W.S.L. incubator.

\section{Acknowledgements}

It is a pleasure to thank the following institutions for their financial support of the OSIRIS project:

- The Communauté Française of Belgium (Action de Recherche Concertée entitled "Pour une histoire matérielle de l'Art")

- The Région Wallonne (DGTRE - First Spin Off project)

\section{References}

[1] Assmann J., Burkard G., Davies V. 1987. Problems and Priorities in Egyptian Archaeology. Londres and New York.

[2] Bell L.D. 1987. The Epigraphic Survey: the philosophy of egyptian epigraphy after sixty years' practical experience. In Assmann J., Burkard G., Davies V. 1987.

[3] Clarke T. 1998. Simple scanners reveal shape, size and texture. Optic Laser Europe, april, pp. 29-32

[4] Loeben C.E. 1996. Anmerkungen zu jüngsten Arbeiten ägyptischer Epigraphik. ARCUS - Berichte aus Archäologie, Baugeschichte und Nachbargebieten, 3, pp. 15-27.

[5] Taubes G. (1999). Virtual Masterpiece. Computer Modeling of a Michelangelo Sculpture. Think Research, 1, pp. 6-9.

[6] Traunecker C. (1987). Les techniques d'épigraphie de terrain. Principes et pratique. In Assmann J. Burkard G, Davies V. 1987, pp. 261-298.

[7] Moreau V., Renotte Y., Lion Y. (2000). Planar integration of polarization-insensitive optical switch with holographic elements, Material Science in Semiconductor Processing, 3, 551-555.

[8] Moreau V., Renotte Y., Lion Y. (2001). Reconfigurable optical interconnect with holographic gratings, Holography (SPIE International Technical Group on Holography semi-annually newsletter), 12 - (2), 7. 